\title{
Selected Reference Books, 2003
}

\section{Eileen Mcllvaine}

This article follows the pattern set by the semiannual series initiated by the late Constance M. Winchell more than seventy years ago and continued by Eugene P. Sheehy. Because the purpose of the list is to present a selection of recent scholarly and general reference works, it does not pretend to be either well balanced or comprehensive. A brief roundup of new editions of standard works is provided at the end of the articles. Code numbers (such as BD111) have been used to refer to titles in the Guide to Reference Books, 11 $1^{\text {th }}$ ed. (Chicago: ALA, 1996).

\section{Religion}

Creeds and Confessions of Faith in the Christian Tradition. Eds. Jaroslav Pelikan and Valerie Hotchkiss. New Haven: Yale Univ. Pr., 2003. 4 volumes + CD-ROM. \$995 (ISBN 0-300-09391-8 [set]). LCCN 2003-043067.

When Jaroslav Pelikan, Sterling Professor Emeritus of History at Yale University, produces a work on the history of Christian faith-no matter how wide the scope-attention must be paid. During a career of nearly fifty years, Pelikan's works have examined Christian traditions and doctrine over a span of sixteen centuries, from their Jewish roots through the tumult of the Counter-Reformation. Now, with Valerie Hotchkiss, a professor of Medieval Studies at Southern Methodist University and director of the Bridwell Library at SMU's Perkins School of Theology, Pelikan has provided a comprehensive and easy-to-consult guide to professions of Christian faith, from its roots in the Hebrew Shema through the recent "Common Declaration" of Pope John
Paul II and Karekin I, the Catholicos of the Armenian Church.

The spiritual ancestor of this work is Philip Schaff's 1877 collection, The Creeds of Christendom (BC311), which, in its revised three-volume edition, includes texts from scriptural roots through earlytwentiety-century Protestant church unions, such as the 1932 combination of the English Wesleyan Methodist Church, the Primitive Methodist Church, and the United Methodist Church into The Methodist Church. Schaff's collection was unprecedented in its scope and thoroughness. He included facing-column English translations in many places-though some early creeds were presented in Greek and Latin only-and began his collection with a doctrinal history of the church.

This new work is divided into four volumes, with an accompanying CDROM that includes texts of all translated works in their original languages, allowing the editors to conserve space and thus include a greater variety of texts. Volume

Eileen McIlvaine is Head of Reference in Butler Library, Columbia University: e-mail: mcilvain@columbia.edu. Although it appears under a byline, this list is a project of the reference departments of the Columbia University Libraries and notes are signed with the initials of the following staff members: Karen L. Green (Ancient and Medieval History Librarian); Mary Cargill, Robert H. Scott, Junko Stuveras, Sarah Spurgin Witte (Butler Library); Fadi H. Dagher (Lehman Library): Nancy Friedland (Media Library); Elizabeth Davis (Music Library). 
I, "Early, Eastern, and Medieval," is subdivided into the early church, the Eastern Orthodox tradition, and the medieval West. Volume II covers the Reformation Era, and Volume III brings the reader upto-date with "Statements of Faith in Modern Christianity." These three volumes were coedited by Pelikan and Hotchkiss; a fourth volume, "Credo," written by Pelikan alone, provides the added value of a general historical introduction.

In addition to the scholarly context Pelikan provides in "Credo," both editors also contribute a brief and more specific introduction to each text, which is followed by a citation for the edition used, translations (where necessary), and a brief bibliography on the text. In addition, each volume contains an extensive bibliography and several very useful indexes. One, bearing the editors' neologism "Syndogmaticon," is a concordance of the individual topics found in the Niceno-Constantinopolitan Creed with those in the other texts in the collection (this particular creed being chosen as the standard by virtue of its recognition by Roman Catholics, Eastern Orthodox, Oriental Orthodox, and all members of the World Council of Churches); this is followed by an alphabetical index to all terms that appear in the Syndogmaticon and thus, in a way, to the entire set.

Pelikan and Hotchkiss also have included an index to all churches, heresies, creeds, and councils included in their collection, recognizing that one man's church is another man's heresy and that it can be tough to tell the players without a scorecard. After these comes a verse-byverse index to all scriptural references included in the collected texts and an index to names of persons encountered anywhere in the four volumes. All four indexes appear conveniently in all four volumes; the bibliography for "Credo" differs from that reproduced in the three volumes of texts.

One might question the classification of these tomes as a reference work: They are essentially three full-text collections with an accompanying monograph. How does that qualify? The indexes, however, make a useful reference work all on their own; the work taken as a whole allows readers to consult, say, the Syndogmaticon or the index of Scriptural references in creedal texts and then have the texts themselves included as a bonus. One-stop shopping.

This work is clearly almost indispensable for any theological library or for any university with a strong religion department, although the price obviously will be a consideration for institutions with tight budgets. The inclusion of translations makes the work accessible to the undergraduate, and the CD-ROM of original texts provides the textual tradition necessary for more advanced scholars.-K.L.G.

Encyclopedia of Religious Freedom. Ed. Catharine Cookson. Routledge Encyclopedia of Religion and Society. New York: Routledge, 2003. 555p. \$188 (ISBN 0-415-94181-4). LC 2003-005354. The 140 alphabetically arranged articles discuss "seven major elements of religious freedom: key concepts, U.S. history, world history, world religions, major issues, minority groups and their rights, and key documents" (Introd.). Each entry is signed and includes a brief bibliography of works in English; references to relevant online sources are occasionally provided.

These essays are even-handed, if a little sanguine, crediting, for example, the British Empire with spreading the idea of religious freedom. Though not intended for a scholarly audience, this should be a useful introductory source.-M.C.

\section{Music}

Bradley, Carol June. Index to Poetry in Music: A Guide to the Poetry Set as Solo Songs by 125 Major Song Composers. New York; London: Routledge, 2003. 900p. \$150 (ISBN 0-415-94302-7). LCCN 2003-271638.

This work contains a comprehensive listing of art songs by 125 Western classical composers. The single alphabetic listing includes names of composers and poets, as well as song titles, and first line of the 
text, if different from the title. Composer entries (in boldface) are the most inclusive, with sub-arrangement by poet and song title. Included with the song title is the date of composition, its publisher, and its location within the collected works of the composer. Poet entries (regular type) are subarranged by composer, with titles listed alphabetically followed by a separate title listing for song cycle titles with composers. Title entries (in italics) contain a "see reference" to the poet and composer; entries for the first lines of text (in quotation marks) contain a "see reference" to the song title, poet, and composer.

This guide for the musically knowledgeable user pulls together an enormous wealth of information, from listing songs by individual composers to identifying settings of the same text by different composers, from providing publication information about song titles to locating individual poems within larger works. This wealth of data is arranged in columns, and distinctive typefaces are used to identify the different data types (as indicated above). The result is a somewhat confusing appearance on the text page, although the typeface examples in the pages' footers provide help for the user.-E.D.

\section{Encyclopedia of World Pop Music 1980 -} 2001. Comp. Stan Jeffries. Westport, Conn.: Greenwood Pr., 2003. 277p $\$ 54.95$ illus. (ISBN 0-3133-1547-7). LCCN 2002-21627.

One hundred thirty-three individuals or performing groups from forty-three different countries are listed alphabetically in this work. Inclusion is limited to those who achieved the largest number of record sales in their own country, with U.S. performers or popularity in the U.S. not relevant for inclusion.

Entries are listed alphabetically by performer's last name or name of the performing group, with each entry containing an overview of the performer or group's career, a discussion of their recorded output and chart placement in the native country, their influence on other artists, and one relevant Web site address.
Appendices include a country breakdown of the performers, a list of the awards given in each country, and each country's silver/gold/platinum sales requirements. A bibliography and index conclude the work.-E.D.

Schneider, Tina M. Hymnal Collections of North America. Studies in Liturgical Musicology, no. 10. Lanham, Md.: Scarecrow Pr., 2003. 207p. \$49.95 (ISBN 0-8108-4706-X). LCCN 2002-154948.

Schneider lists 326 major library collections of hymnals in North America, as well as those in private hands where the owner allows access to researchers. The list is organized alphabetically by U.S. state or Canadian province, with sub-arrangement by city, followed by name of the institution or owner. An entry includes street address, contact and access information (personal contact, phone, fax, e-mail, etc.), and descriptive annotation. Following the directory entries is an extensive bibliography organized into four parts: Studies of Hymnals by Denomination, Studies of Hymnals across Denominations, Descriptions of Hymnal Collections, and Reference Works in Hymnology. Four indexes conclude the work: Index of Denominations and Religions; Index of Hymnal Languages and Places of Origin; General Index; and Index of Chronological Holdings.-E.D.

\section{Cinema}

Keaney, Michael F. Film Noir Guide: 745 Films of the Classic Era, 1940-1959. Jefferson, N.C.: McFarland, 2003. 541p. illus. $\$ 75$ (ISBN: 0-7864-1547-9).

Coined by French critics after World War Two, "film noir" or "black film" defined an indigenous American form. Many of the films were directed by émigrés strongly influenced by the German Expressionist period and shared elements of alienation, obsession, crime and murder, money, power, or sex. The films also are characterized by urban, almost always American, settings and defined by a distinct narrative and visual style. Despite these shared characteristics, film noir is 
not easily characterized as a genre or movement or as a style of filmmaking.

The Film Noir Guide, published by McFarland, is an attempt to expand and revise the canon of film noir films made during 1940-1959. Michael F. Keaney, a first-time author, identified (and viewed) the 745 films included in this guide. In comparison, Robert Ottoson's A Reference Guide to the American Film Noir: 1940-1958 (Metuchen, N.J.: Scarecrow, 1981. 285p.) contains just over two hundred entries. Keaney's enthusiasm for the material is evident. He feels close enough to his subject matter that he refers to the actor Humphrey Bogart as "Bogey." Unfortunately, this work does not contain any serious background or supplemental discussion, nor was it compiled with a credible methodology. It also does not make a clear distinction between those films considered film noir and those simply containing "noir-like" elements.

The format of the guide includes short plot summaries (without giving away the ending) for each film, release dates, main performers, screenwriters, directors, type of noir (his own highly subjective classification), film's thematic content, and a rating based on a very subjective five-star system. In addition, appendices provide lists by director, type, year of release, a guide to building an affordable collection (including taping from TV), a bibliography, and an index.

The methodology used to complete the list is uneven in credibility. Keaney describes pulling titles from books on film noir, Internet lists, personal recommendations, films advertised by video dealers as film noir, and films described by film historians and critics as being in the noir style. As a result, Keaney has expanded the canon of film noir to include westerns, comedies, and period films. Basically, he has included genres generally excluded from film noir classification. If his intention is to open the discourse on film noir, he should at least provide an argument or discussion for doing so. Keaney does acknowledge, however, that some purists may disagree with this work.
Instead, justifications for the entries are cited in the categories of type of noir and film noir themes. This classification is highly subjective and broad-ranging. The film noir types include: boxing, gambling, heist, triangle, impersonator, horror, wrong woman, fantasy, on the run, good twin-bad twin, horse opera, hostage, gangster, religion, Nazi, psycho- - the list goes on. The film noir themes range from obsession, jealousy, and greed to revenge, betrayal, and so on.

Supplemental information such as the actors who went on to television stardom has nothing to do with the content of the work. This information might be better served in a separate reference work with focus on actors who went from the big to the small screen. Equally, the star rating system and noir moments work well in resources such as the online Internet Movie Database but lose utility in this reference work. This type of e-entertainment information does not serve a significant purpose in a reference guide on film noir.

Another disturbing curiosity of this work is the appendix entitled "How to Build an Affordable Collection-including Taping from TV." The reader might want to check copyright status before following this advice.

Alain Silver and Elizabeth Ward's Film Noir: An Encyclopedia Reference to the American Style (1992. 479p. BH224n) remains the standard reference work on film noir. Now in its third edition, the single-volume work is a more conservative catalog of film noir films. More importantly, the introduction and the appendices lay out the issues of debate of style, genre, or auteurish study, providing the reader with a basis for study and understanding of each film's inclusion. The appendices provide discussion on why westerns, comedies, and gangster films, though sharing many elements of film noir, are not film noir. "The determining factors in excluding productions from the comedy, gangster, Western, and period genres are simple. The concept that the action of film noir must be grounded in a 
contemporary setting excludes Westerns and period films. The concept that film noir must have a narrative that is dramatically developed with an underlying seriousness and verisimilitude in exposition excludes comedies. The concept of a complex protagonist with an existential awareness of his or her situation excludes the gangster film" (Appendix A).

Keaney acknowledges that the film noir debate over genre, style, or movement is ongoing but does nothing to fuel the debate or alert his readers to the fact that even though a film is included in the Film Noir Guide, it is not necessarily a film noir film. He states, "While it's not within the scope of this book to go into detail about the ongoing controversy over the definition of 'film noir,' I will say a few words about it. (A few of the many books that cover this in great detail are included in the bibliography for those who want to delve further into this interesting, but futile, debate.) Some film historians and critics believe that film noir is a genre, while others believe it's simply a style. Some squeeze themselves right into the middle, claiming it's a genre in which style plays an important part. Others say it began as a style within the B film genre and developed into a genre itself. Still others believe it's a "movement" or a "cycle." Most film noir fans I speak with tell me that they don't really care whether it's a genre or a style or a cycle. It's all very interesting, they say, but they'd rather leave the argument to the professors and critics to iron out. It takes time away from collecting and viewing these incredible films, some of which are masterpieces of American moviemaking and some of which are turkeys" (Pref.).

Clearly, this work is not intended for researchers or scholars.-N.E.F.

Making Pictures: A Century of European Cinematography, Created by Imago, The Federation of European Cinematographers. New York: Abrams, 2003. 464p. \$65 (ISBN: 0-8109-4385-9). LCCN 2003-102210

Making Pictures: A Century of European Cinematography is a celebration of cinema- tographers and the art of filmmaking and is nothing less than a stunning achievement. It is a handsome work in celebration of the cinematographer as creative artist and collaborator, not only as a technician and camera operator. The work was created by IMAGO, the European Federation of National Cinematographers Associations, an organization founded to uphold the highest standards achieved by the cinematography profession, and published by Harrry N. Abrams, who is considered to be one of the preeminent American publishers of high-quality art and illustrated books. (Abrams recently published Robert Sklar's Film: A World History of Film. 2003). The textual content of the book begins with essays by filmmakers including several cinematographers (e.g., Sven Nykvist), the director Bernardo Bertolucci, and the actor Marcello Mastroianni. The filmmakers discuss their craft, their relationship to cinematography, and the art of filmmaking. Not simply anecdotal, these short essays are rich in insight and shared experience, highlighting the essential interplay between cinematographers and all other filmmakers involved in the shooting.

What follows is an extensive and richly informative history of European cinematography, actually a history of European cinema. The history begins with the early photographic technologies and advances through the silent period, Germany in the Weimar period, avant-garde, talkies, color, and beyond. Even though the focus is on the advancements in filmmaking technologies such as camera work and lighting; the essay provides a rich history identifying key directors, films, genres, and movements. This discussion is followed by an extended essay on cinematographers and their medium. This entry discusses cinematographers as artists and how essential their role is as creative collaborators versus merely technicians.

The central focus of the book contains a hundred feature films, chosen by jury, representing the highest quality of European cinematography. The films are discussed 
in relation to the cinematographer's work, why lighting and technical choices were made for effect and purpose. The films are arranged chronologically-generally, one per year beginning with 1895-1995. The entries are well written and provide a discussion of the cinematographic highlights of each film. The entries are brilliantly enhanced by exquisite still photographic reproductions that illustrate the techniques of lighting, focus, and camera work used in the film. The stills are annotated with specifics on how the scene was shot and lit from varying angles, providing the necessary visual component to understanding concepts and techniques of filmmaking. The photographic reproductions are of the highest quality and found throughout the book.

The catalog of films is then followed by an extensive and informative section entitled the "Tools of the Trade," which provides an in-depth history of cameras and equipment. Bibliographic references and indexes are included.

This title is essential for academic libraries supporting a film studies program and highly recommended for all other libraries, academic and public.-N.E.F.

\section{Sports}

Loverro, Thom. The Encyclopedia of Negro League Baseball. New York: Facts on File, 2003. 368 p. $\$ 75$ (ISBN 0-81604430-9). LCCN 2003-01075.

Written by a Washington Times sports columnist, this encyclopedia does not replace the more detailed and complete Biographical Encyclopedia of the Negro Baseball Leagues by James A. Riley (N.Y.: Carroll \& Graf, 1994. 926p.). But it does offer new stories, anecdotes and quotations, and photographs of players, managers, and teams, which makes it a valuable addition to any large reference collection. Indexed, with a brief bibliography that surprisingly does not mention the Riley encyclopedia or John Holway's Complete Book of Baseball's Negro Leagues (Fern Park, Fla.: Hastings House, 2001. 510p.), the standard compilation of Negro League player statistics.-S.S.W.

\section{Political Science}

Graham, Thomas Jr., and Damien J.

LaVera. Cornerstones of Security: Arms Control Treaties in the Nuclear Era. Seattle: Univ. of Washington Pr., 2003. 1,487p. \$125 (ISBN 0-295-98296-9). LCCN 2003-1145

This resource owes its existence to efforts undertaken in the 1970s by the U.S. Arms Control and Disarmament Agency (ACDA) to compile the texts of disarmament treaties. That effort resulted in the publication of Arms Control and Disarmament Agreements: Texts and Histories of Negotiations, which was partially updated in 1996. Cornerstones of Security builds on that useful endeavor. Essentially, it provides the text of treaties related to containing and halting the proliferation of weapons of mass destruction. It also adopts a broader focus and includes more recent treaties seeking to restrain small arms trafficking and to ban land mines. The layout of the treaties is chronological with an introduction and a conclusion serving as contextualizing bookends. Each treaty is prefaced by a new or updated summary and analysis in which the authors place the treaty within an historical and international context.

Both Graham and LaVera infuse the book with their own personal and professional insight and knowledge in the field. Before retiring in 1997, Graham served as acting director of the ACDA and as U.S. Special Ambassador for Disarmament. He is the author of Disarmament Sketches: Three Decades of Arms Control and International Law. Currently, Graham serves as chairman and LaVera as coordinator of the Lawyers Alliance for World Security, based in Washington, D.C.

The book includes a list of abbreviations and acronyms, an appendix with country names affiliated with a treaty, date of country's signature, and date of deposit of ratification. It is oriented toward diplomats, international lawyers, arms control specialists, and researchers in the field of international security. Recommended for specialized reference collections.-F. H. D. 


\section{History}

Campbell, Gordon. The Oxford Dictionary

of the Renaissance. New York: Oxford

Univ. Pr., 2003. 862p. illus. \$150 (ISBN

0-19-860175-1).

The Renaissance is roughly defined as a time period from 1415 to 1618 , with some geographical variants. This is basically a dictionary of cultural history of early modern Europe excluding Arabic, Celtic, and Ottoman territories, but with an emphasis on Continental Europe. Political figures are, however, included as patrons of arts and as the background to intellectual history. The editor treats culture broadly including law, theology, science, and popular culture. The book is intended for specialists who seek information outside their specialization, students looking for introductory work, and general readers in need of a reference guide.

Preceding the usual alphabetical entries is the thematic index, which arranges article themes by subject field. For example, under the "Thought in the Renaissance," one finds subdivisions such as "Philosophy in the Renaissance," "Philosophers," "Political Philosophers," "Polemicists," and "Theologians." Then, under "Philosophy in the Renaissance," topics such as Cicero in the Renaissance and Vindicae contra tyrannos are grouped.

The thematic index is not a complete index of articles. The fact should have been spelled out. "Religion in the Renaissance" has a subdivision titled "Protestant Reformers and Leaders," which includes Martin Luther and a number of other leaders. Neither Calvin nor Théodore de Bèze appears there, although there are articles under their names in the main body of the book.

Articles are short to medium in length and have a short bibliography, often a reference to one of the standard, major biographical and subject dictionaries such as DNB (Dictionary of National Biography. AH226). Most cited references are in English. The book is illustrated with blackand-white photographs of art works. The appendices section has a table of ruling houses; place names in imprints; a table of the dates when the Gregorian calendar was adopted in states, cities, bishoprics, etc.; and, finally, "Ligatures and Contractions in Renaissance Greek."

Recommended to anyone who is interested in the complex and varied manifestations of the Renaissance throughout the 200-year history of Europe.-J.S.

\section{Cook, Chris, and John Stevenson.}

Longman Handbook of Twentieth-century

Europe. London, New York: Pearson/

Longman, 2003. 404p. maps. \$28 (ISBN 0-582-23508-1).

The two authors of British Historical Facts (DC323n) and Longman Handbooks on Modern Europe (DC21) now offer this handbook for the study of Europe in the 20th century. The emphasis is on political, social, and economic history. The book is divided into seven sections. The first section is a collection of chronological tables by topic, such as Fascist Italy, the Holocaust, and formation of the European Union. Section two consists of lists of heads of state by country (sovereigns, presidents, prime ministers, etc.) with dates. Section three covers armed conflicts in and out of Europe from Russo-Japanese War (1904-1905) to the ongoing RussiaChechnya war in paragraph-length descriptions, followed by chronological tables of nuclear rivalry and arms control since 1945, wars of decolonization, treaties and alliances, and international organizations.

Sections four through six are respectively "Social and Economic History," "Biographies," and "Glossary of Terms." "Social and Economic History" consists of statistical tables (population, key commodities such as wheat, coal, oil, and electricity) and chronological tables (religious history, women, social welfare). Some of the statistical tables are reprinted from Mitchell's European Historical Statistics (CG189). "Biographies" has succinct descriptions of the role each person played in 20th-century European history and includes a wide range of statesmen, politicians, and soldiers from Clemenceau to 
Berlusconi. It includes not only Hitler and De Gaulle, but also Anne Frank and Cohn-Bendit. "Glossary of Terms" provides concise and clear definitions of terms that frequently appear in discussions of 20th-century European history and politics. The final section, "Topical Bibliography," is a bibliographical essay with lists of sources, documents, and secondary works arranged by time period and country. Along with sources, a few essay topics are suggested. The book ends with ten maps depicting Europe from 1914 to 1997 and the convenient subject index.

This is a useful addition to history and political science collections in college and university libraries.-J.S.

Encyclopaedia AEthiopica. Ed. Siegbert Uhlig. Wiesbaden, Ger.: Harrasowitz Verlag, 2003. Vol. 1 (ISBN 3-447-047461). (In progress, to be in five volumes.) Given the current fashion among many publishers for "encyclopedias" that are really little more than random collections of essays on a more or less cohesive topic, it is refreshing to be able to greet the appearance of a subject encyclopedia that makes a truly new contribution to the reference field and is surely destined to be the classic resource in its area for years to come.

Encyclopaedia AEthiopica sets out to document the history, society, and culture of the peoples and politics on the territory of present-day Ethiopia and Eritrea, from prehistoric times down to the middle of the 20th century. The unique and complex matrix of cultures whose development can be traced here over the course of many centuries has long attracted the attention of an international community of scholars, because of both its intrinsic fascination and the interesting comparative light its peculiar mix of African, Christian, Islamic, and Jewish elements sheds on the history of each of those traditions. Throughout much of that history, the region has been remote-or even isolated-from the rest of the world, and even today, it remains poorly known to the average educated reader and only partially covered by mainstream reference sources. Hence, the value of this broad new information source.

The collective work of a large international team that includes many of the leading specialists in the field, the encyclopedia will, when completed, consist of four volumes of text and an additional index and supplement volume. Judging from the one volume currently available, the more than 4,000 articles it contains will cover a broad range of topics, including biographies of political, cultural, and religious figures and prominent scholars of Ethiopia; overviews of individual ethnic groups and languages; and discussions of historical events; literary works; geology and geography; plant and animal life; cultural artifacts; economic activities; art, architecture, and antiquities; titles and offices; liturgical forms and theological issues; institutions and laws; holidays and customs; and much more. Among the many achievements of this survey is the detailed coverage given to the whole range of peoples and cultures of the region, in contrast to the heavy emphasis on the Semitic-language peoples of the highlands found in many other surveys. Individual articles are signed and include an authoritative list of sources and secondary literature. The text is supplemented with a generous number of illustrations, maps, and charts. Extensive cross-references direct the reader to related entries.

Given the excellence of the coverage provided, it is somewhat disappointing that the editors have chosen not to treat the events of Ethiopian revolution and the country's experience under a Marxist regime, except in occasional passing references. After all, this is now something of a closed chapter in the region's history and one that surely had a profound impact on the world presented to us here. Certainly, there are many other sources documenting the more recent history of Ethiopia and Eritrea, but it is unfortunate that we do not have the chance to benefit from the expertise of this team of special- 
ists and their colleagues in addressing those questions as well.

By any measure, this is an outstanding achievement, comparable in its authority and scholarship to such classic reference sources as The Encyclopaedia of Islam, Lexikon des Mittelalters, or Dictionnaire d'histoire et de géographie ecclésiastiques. It will certainly serve as a reliable reference for specialists in the field but should provide valuable guidance for the beginning student and layperson as well. Indeed, given the wealth of information it brings together from sources not readily available in every collection and the rich system of cross-references, the set will be able to serve as a very browsable, hypertextual introduction to Ethiopian studies in general. It belongs in every library with serious coverage of Ethiopia and African studies, but it should be seriously considered as well for collections where it could serve as the single key source for the region's history and culture.-R.H.S.

\section{Golay, Michael, and John S. Bowman.}

North American Exploration. Hoboken, N.J.: John Wiley, 2003. 518p. illus. $\$ 40$ (ISBN 0-471-39148-4). LCCN 200227434.

This is a handsome volume with lots of white space, attractive typeface, clear and relevant illustrations. The text is well written and arranged in seven parts geographically then chronologically: (1) "North America before Columbus"; (2) "The Spanish Enter the New World, 14921635"; (3) "Atlantic Seaboard, 1497-1680"; (4) "Exploring West of the Mississippi, 1635-1800"; (5) "From the Appalachians to the Mississippi, 1540-1840"; (6) "Across the North American Continent, 1720 1880 "; (7) "The Arctic and Northernmost Region, 1576-1992." Within each section, alphabetically arranged, there are short essays for explorers, expeditions, geographical areas (e.g., Blue Ridge Mountains). Many of the entries are accompanied by a portrait of the explorer, photograph of the area, or a brief extract from a letter, diary, or report with the title of the source.
The volume ends with a bibliography of books arranged to accompany each part (pp. 493-97), and an index (pp. 498-518). One could quibble about the lack of some entries in the index (e.g., the Lost Colony does not appear nor is it a cross-reference under Roanoke Colony, Outer Banks, or North Carolina).

North America is defined as including Mexico, Central America, the Islands of the Caribbean, the United States, Canada, Greenland, and the Arctic Regions up to the North Pole. Disputed claims are described (e.g., the Greek, the Chinese; discussed are instruments and methods of navigation, the papal bull that made Brazil part of the Portuguese empire). The last entry in the volume is for Hubert Wilkins, who after flying over the Arctic, bought a submarine from the U.S. Navy for one dollar and tried to sail under the Arctic to the North Pole. This did not work because the sub had to surface every 125 miles.-E.M.

Smele, Jonathan D. The Russian Revolution and Civil War, 1917-1921. London, New York: Continuum, 2003. 625p. \$110 (ISBN 0-8264-5618-9).

In many respects, this work represents the very best in subject bibliography. To begin with, it fills a critical need because, incredibly enough, there has not been, to date, a comprehensive annotated bibliography devoted to the English (and West European) language literature on the Russian Revolutions and Civil War of 19171921, a key turning point not only in the history of Russia, but of the world as well. As author Jonathan Smele notes, readers looking for coverage of this literature have been able, in the last few years, to make good use of Murray Frame's The Russian Revolution, 1905-1921: A Bibliographic Guide to Works in English (Westport, Conn.: Greenwood, 1995), but that work's broader chronological range, smaller number of overall entries, and absence of annotations did not preclude the need for a fuller work such as the one under review here. Moreover, although no volume dealing with as vast a topic as 
this can ever claim full comprehensiveness, this one probably comes as close as practicably possible to that goal.

The breadth of coverage is impressive: A series of twenty-five sections surveys bibliographies and reference works; documentary and narrative sources; general surveys and studies of specific stages and events of the revolution and civil war; the late imperial Russian background (a selection of works only); the Russian army; early Soviet state, society, economy, and foreign policy; contemporary foreign reactions; German occupation and Allied intervention; the White movement and popular resistance to the Bolsheviks; the history and leaders of the Bolshevik and other key political parties; workers and urban society; the peasantry and agriculture; national minorities and regional affairs; and (more selective coverage of) the arts, science, culture, education, religion, and historical fiction. Among the areas that seem to have much fuller treatment here than in earlier surveys are the extensive coverage of non-Russian groups and areas and an examination of the revolutionary events in the context of the broader upheaval of the First World War. It is hard to miss the fact that purely social historical treatments are far overshadowed by political and military treatments, but this is probably a reflection of the literature itself: a quick examination of online bibliographic sources did not uncover any obvious areas of omission.

The real glory of this work, however, lies in its annotations. An incredible amount of careful, intelligent work has gone into their creation. It is an impressive achievement. The reader is provided, typically, with a substantive statement of the significance and quality of the work, and frequently with a précis of its main thesis, and often with some indication of where it fits into the general schools of historiography. In many cases, these abstracts rise to the level of capsule reviews. Every secondary work that was examined (and most of them were) is provided with such an annotation, as are many of the primary sources, except for items such as contemporary newspaper accounts whose titles already make the focus of their coverage clear.

Arguably, no specialist on the revolution will want to ignore this work. Indeed, one can anticipate it becoming part of the stock in trade of all graduate students in Russian history. Indeed, anyone doing research or writing on the revolution should probably consult this bibliography.

But there's the rub. In an age of increasing online access to bibliography, information seekers are turning less and less frequently to print sources, a fact reflected dramatically in the field of publishing. (A search for books with the word "bibliography" in their title or subject heading in the OCLC database reveals a steep and steady decline in the genre, from a high of 11,420 hits with an imprint date of 1980 to just 4,251 with an imprint date of 2000.) Indeed, the book itself invites some frustrating comparisons with an online format. The number of cross-references is minimal, and there is only an author index, so that, one must carefully navigate the very detailed table of contents to find the material one needs. Even though there is rich information in the annotations, one can benefit from it only if one has the time and commitment to browse.

It is to be hoped that the publishers of good subject bibliographies in print will soon find strategies for delivering that content in some type of electronic format. An individual doing research on the railroads in the revolution, or Vladivostok, or War Communism in this valuable collection would benefit enormously from even a simple keyword search. Smele has done a superb job of describing the literature of this topic. That valuable content could be exploited much more effectively were it to be presented in the formats now possible as a result of evolving technology.-R.H.S.

\section{History, United States}

Atlas of American Military History. Ed. James C. Bradford. New York: Oxford Univ. Pr., 2003. 245p. illus. \$50 (ISBN 0-19-521661-X). LC 2003-037907. 
This is a collection of illustrated essays by various scholars discussing military engagements by the United States, arranged chronologically from the Colonial Wars (1512-1774) to the Post-Cold War Era: 1900- (which includes the 2001 Afghanistan War). Some essays are on specific wars, such as the Civil War or the Spanish-American War, but many deal with general themes, such as "The Growth of the Professional Army: 181560 " or "America's Rise to World Power: 1867-1917," making this more a survey of America's military past than a true military atlas.

Students wanting a very detailed illustration of the progress of the battle of Gettysburg, for example, will need more than the 4 " $\times 6$ " drawing in the chapter on the American Civil War, but the 30page essay is a very good introduction to the military aspects of the war overall.

There is a bibliography at the end of the book, arranged by chapter heading, so a student can get very useful further leads, and this should serve as a useful introduction to the subject.-M.C.

\section{U.S. Congressional Serial Set-Digital Edi-}

tion. Newsbank, 2003-. Available online from http:/ /infoweb.newsbank.com/. Subscription price varies; $\$ 152,000$ for large ARL institutions.

The Serial Set's more than 13,000 volumes are an essential source of American history, (AF87-AF91 and p. 254) and Newsbank is making it available online. Currently the 15th, 16th, and 17th Congresses (1817-1823) have been issued, and December 2008 is the projected completion date. Though the dates covered are listed as 1817-1980, the American State Papers are promised in the subscription price.

The contents of the Serial Set are broad, and Newsbank has created subject headings for each document; these are new headings, not related to those used in the CIS US Serial Set Index (AF87). The use of a controlled vocabulary instead of relying on the ambiguities and confusion of full-text searching (especially when vocabulary has varied so much over 200 years) is welcome, but the subject indexing is a bit problematic. The subjects are grouped under eighteen broad topics, such as armed forces and conflicts, health, international affairs, social issues, and narrower terms are listed if the reader clicks on one of those headings. There are no cross-references or links, so basically a careful user would have to read through several hundred terms to make sure he did a thorough subject search. (What will happen when 150 years' worth of subjects is included is anybody's guess.) Some Indian tribes, for example, are listed among "Groups of People," "Professions," etc., alphabetically by tribal name amidst all other groups. "Indians" (51 entries) is also among "Groups of People," but it is not clear whether the publications relating to the individual tribes are included in that number. Nor is it clear how much authority work has been done: What tribe are the Stockbridge Indians? Indian tribes are also among the terms listed under "Social Issues" (along with such terms as art, corporal punishment, sedition, reference sources, and many other seemingly unrelated terms). A series of unrelated, single words does not appear to be a really useful way to index the vast and varied resources of the Serial Set.

The searching, too, is problematic. There is a simple search, which allows for a single term (though searches can be refined within one of the eighteen subject areas), and an advanced search, which allows for two terms, or to "not out" a term. Because many of the publications apply to private individuals, it should be possible to eliminate these, but though "not personal name" is an option, it doesn't seem to work. It is possible to limit the search to reports on public (as opposed to private) bills, but this does not appear to apply to documents.

It is also possible to search by title. Of course, titles of items in the Serial Set are somewhat fluid, as titles in the various official and unofficial sources sometimes vary. I tried a few titles listed in the Guide to American Indian Documents in the Congressional Serial Set: 1817-1899, some of which did not 
turn up as cited. I also tried searching the titles from a volume of the Serial Set itself; the titles on the items themselves were all found, but some of the titles as listed in the table of contents took some ingenuity to locate. Of course, it is impossible to imagine how any source could come up with all the various titles that have been used, but there could be some context sensitive help which explains the issues.

The problems with subject and title searches are probably fairly minor because many, if not most, people using the Serial Set will come to it via another reference and will have the Congress and the report or document number. Unfortunately, searching by number is even more confusing than searching by title or subject. I could find no guidance in the help screens, under either simple or advanced searching. The standard convention of

15-1 (Fifteenth Congress, first session) does not turn up anything. There is no example or explanation of searching for reports or documents, which is, of course, what makes up the Serial Set. There is a search term called "publication number," but no further clues are given. Playing around with various styles, I found that an advanced search of $15 / 1$ as the Congress/session number and h.doc 60 as the publication number found H.doc 60 for both sessions. There does not appear to be a simple way to figure out how this most elementary and basic search is done, though items can be found using persistence and imagination.

It is possible to print a single page, selected pages, or the entire document, so when the items are located, this is a very useful source. However, libraries considering purchase may want to examine the forthcoming LexisNexis version of the Serial Set as well.-M.C.

\section{Women's Studies}

McDevitt, Theresa. Women and the American Civil War: An Annotated Bibliography. Westport, Conn.: Praeger, 2003. 245p. Bibliographies and Indexes in Women's Studies, 32. \$64.95 (ISBN 0313-32105-1). LCCN 2003-047239.
This is a very useful bibliography on the contribution of women to the Civil War effort. It has a topical arrangement, with sections on: soldier's aid; medical and relief services; aid to freed people; economic challenges and opportunities; women in the war zone; spies, scouts, smugglers, and raiders; and women in camp. Each chapter includes an introduction giving a chronological overview of the topics and identifying important and primary and secondary texts. This is followed by an annotated bibliography of entries arranged by author. If the text is available in "Making of America" or other Internet collections, the URL is listed. Each chapter closes with annotated lists of Internet sites. There also are three general sections: "Reference Works," "Introductory Works," and "Anthologies," which is further subdivided by topic (e.g., Southern women, state and local studies); and other topics not fully explored (including military wives and daughters, and women in public life). It concludes with author and subject indexes.

With only 800 entries, Women and the American Civil War does not provide comprehensive access to the topic. It cites 19th-century books, but no 19th-century periodical articles, and most of the 20thcentury articles cited could be found searching America: History and Life (DB24). This is nonetheless an excellent introduction to the topic, one that lists all of the important resources and will be indispensable to reference librarians in libraries of all sizes.-S.S.W.

\section{New Editions and Supplements}

Continuum has reissued its Encyclopedia of American Literature (1999. 1305p.), which is now called the Continuum Encyclopedia of American Literature (2003. 1305p. \$49.95). Both are edited by Steven Serafin. The difference seems to be the addition of some death dates.

Peel's Bibliography of the Canadian Prairies to 1953 in its third edition has reached 7,429 entries with 1,103 more in the annotations (eds. Ernie B. Ingles and N. Merrill Distad. Toronto: Univ. Toronto Pr., 2003. xxviii, 899p. il. $\$ 125 ; 1^{\text {st }}$ ed. 1956 ; 2 d 
ed.1973. (DB216). The cut-off date, 1953, is a reflection of the beginning of the National Library of Canada's copyright deposit program. Peel is Bruce Braden Peel, the compiler of the first edition. The author index includes biographical notes.

Papers of British Antiquaries and Historians is volume 12 of the Guides to Sources for British History (DC287), now issued by The National Archives formed by the merger of the Historical Manuscripts Commission and the Public Record Office (London: 2003. 246p. £30). The volume identifies and briefly "describes the papers of thirteen hundred antiquaries and historians, genealogists, heralds, archaeologists and others working in England, Wales, Scotland and Ireland between the mid-fifteenth and the late twentieth century" (back cover). For each, it gives a brief descriptive phrase, the institution holding the papers, and an indication of the contents and any published guides.

Tom Zaniello has reissued his amusingly titled guide: Working Stiffs, Union
Maids, Reds, and Riffraff: An Expanded Guide to Films about Labor (Ithaca: ILR Pr./Cornell University Press, 2003. 434p. \$24.95, 1st ed. 1996). Now intended to cover 350 films, most available in videocassette, it now is global with films from every major country or geographical area (e.g., the Caribbean). Representative titles include 10,000 Black Men Called George, I Can Get It for You Wholesale, The Solid Gold Cadillac, Tobacco Road, and the Gold Diggers of 1933. Reviews for further reading are included.

The Dictionary of Bibliographic Abbreviations Found in the Scholarship of Classical Studies has grown from 393 to 684 pages (Westport, Conn.: Praeger, 2003. \$19.95. 1st ed. 1983. BE1019). Jean Susorney Wellington, the compiler, had added some 1,250 new titles, included abbreviations for Internet resources, and added more regional and archaeological publications. No longer "limited to journals, series, and standard monographic works," "classical studies" has been defined broadly to cover all aspects of ancient Greece, Rome, and now "allied fields." 